\title{
Historical Research through the Lens of Women: The Ming Qing Women's Writings Digital Archive and Database*
}

\author{
Grace S. Fong* \\ McGill University \\ ${ }^{*}$ Corresponding author. Email: grace.fong@mcgill \\ doi:10.1017/jch.2020.20
}

\begin{abstract}
This essay provides an overview of the goals, main features, and digital tools of the Ming Qing Women's Writings (MQWW) project, which contains more than 400 collections of literary writings by women $\left(17^{\text {th }}-\right.$ early $20^{\text {th }}$ centuries). The website (http://digital.library. mcgill.ca/mingqing/) makes accessible a free archive of scanned images of texts with searchable components and a downloadable database. It highlights MQWW's functionalities and actual and potential applications for literary, biographical, and historical research.
\end{abstract}

Simply stated, the purpose of the Ming Qing Women's Writings digital archive and database project (hereafter MQWW) (http://digital.library.mcgill.ca/mingqing/) is to make freely accessible online the digitized images of a large number of collections of writings by women held in the project's participating libraries for research from anywhere in the world. ${ }^{1}$ MQWW provides effective and powerful research tools for scholars and students interested in Chinese literature, culture, and history, especially in women's poetry and literary culture, history of women's publishing, women's kinship and social networks, and the temporal and geographical distribution of authors (both male and female) and texts. The majority of the more than 400 collections are xylographic prints (keben 刻本) from the late Ming (1368-1644) and throughout the Qing (1644-1911), with some xylographic, lithographic (shiyinben 石印本), stereotype (qianyinben 鉛印本), and typeset (paiyinben 排印本) editions from the Republican

*The Ming Qing Women's Writings project would not have been possible without the initial generous funding by the Richard Charles \& Esther Yewpick Lee Charitable Foundation of Hong Kong and the collaboration with the Harvard-Yenching Library (2003-2005). I am also grateful to subsequent funding from the Social Sciences and Humanities Council of Canada, the Henry Luce Foundation of the US, and others; and to the support provided by all the participating libraries, not least of all McGill University Library. I am deeply indebted to the dedicated work of graduate assistants at McGill, Peking University, and East China Normal University.

${ }^{1}$ They are, in the order of collaborating in the project, Harvard-Yenching Library (2003-2005), Peking University Library (2008-2009), Sun Yat-sen University Library (2011-2015), National Library of China (2012-2019), East China Normal University Library (2012-2018), Chinese University of Hong Kong Library (2018-2019), Hong Kong Baptist University Library (2018). 


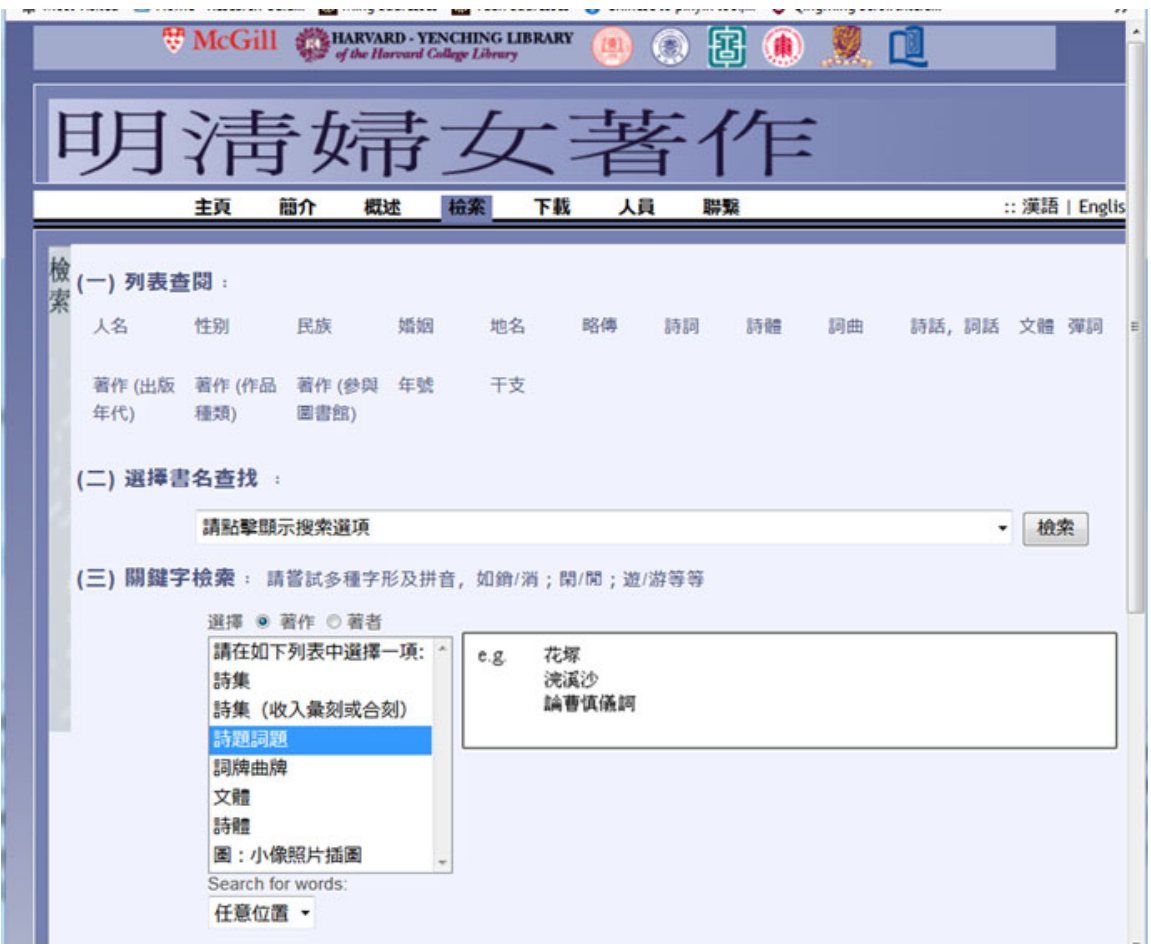

Figure 1. Search page, http://digital.library.mcgill.ca/mingqing/search/index_ch.php

period (1911-1949). There are also some hand-copied manuscripts (chaoben 抄本 / 鈔本). ${ }^{2}$

One can search MQWW in both Chinese Traditional Characters and Pinyin romanization. It provides many access points for searches, including but not limited to name of author, title of collection, poetic form, and region (Figure 1) The full records contain much rigorously verified data. Each collection is accompanied by its analyzed table of contents. (Figure 2) Although not a full-text database-a distant goal-MQWW is searchable based on an extensive set of metadata. Research data for generic, thematic, and other topical categories can be searched by code words (keywords) determined by the individual researcher. ${ }^{3}$ In addition, users can link between women based on

\footnotetext{
${ }^{2}$ There are at the time of writing 384 collections in MQWW. The total will be more than 400 after the December 2019 update.

${ }^{3}$ Examples of publications that utilize data and texts from MQWW are essays in The Inner Quarters and Beyond: Women Writers from Ming through Qing, ed. Grace S. Fong and Ellen Widmer (Leiden: Brill, 2010); Xiaorong Li, "Eating, Cooking, and Meaning-Making: Ming-Qing Women's Poetry on Food," Journal of Oriental Studies 45.1-2 (2012), 27-44; Yanning Wang, Reverie and Reality: Poetry on Travel by Late Imperial Women (Lanham: Lexington Books, 2014). PhD dissertations and MA theses produced in China, Taiwan, and Hong Kong have also drawn on texts and data from MQWW (personal communication from colleagues and students), e.g., Wang Yiyun 王怡云, “Nüxing zuowei zuozhe: cong shige de jiaodu chongkan Qingdai nüshiren” 女性作為作者 : 從詩歌史的角度重看清代女詩人 ( $\mathrm{PhD}$ diss., Guoli Chenggong daxue, Taiwan 2014).
} 


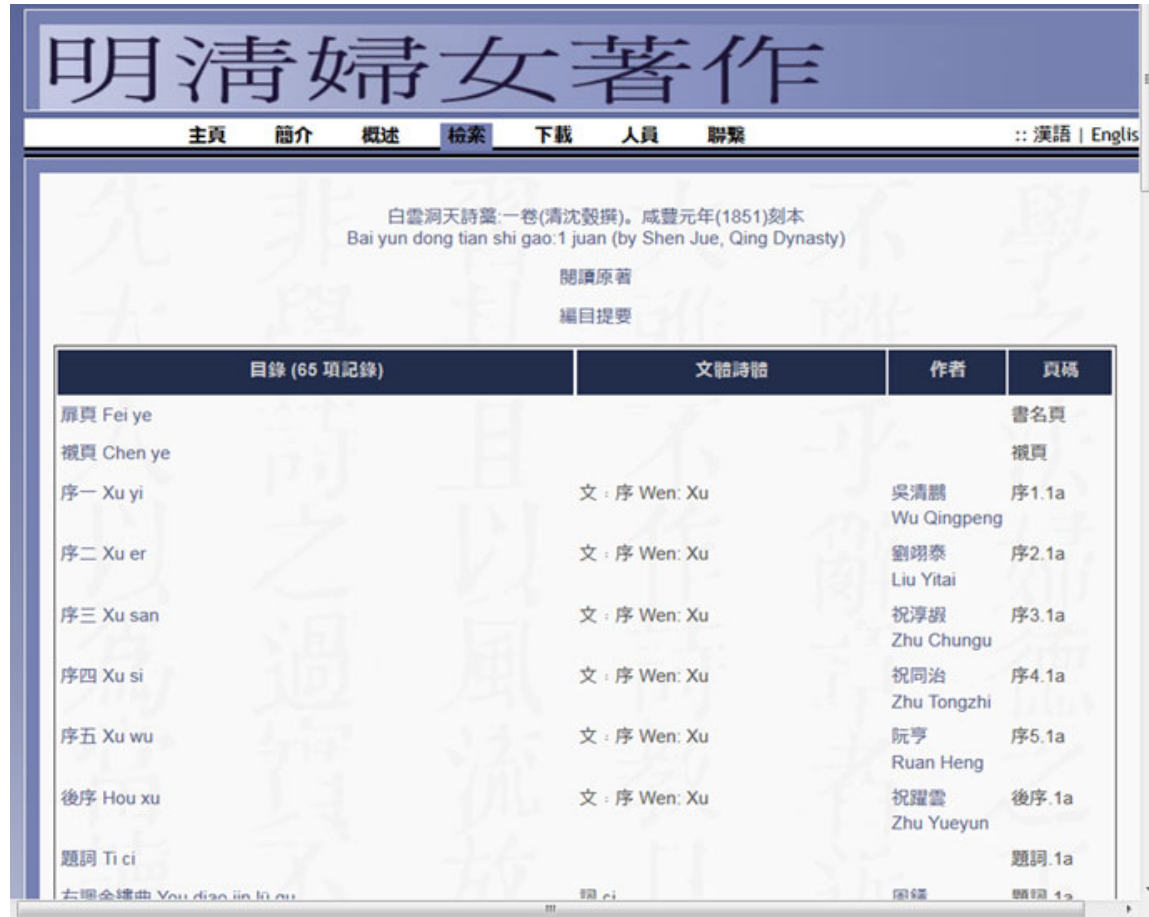

Figure 2. Table of Contents: Bai yun dong tian shi gao 白雲洞天詩莕 (1851 ed.) by Shen Jue沈瑴 (nineteenth century), http://digital.library.mcgill.ca/mingqing/search/results-work.php?workID = 244\&language = eng

poetic exchange and correspondence, obtain contextual information on family and friends, and note the ethnicity and marital status of the women writers, among other data fields. Each discreet text within a collection, whether a preface, poem, song lyric, prose essay, biography, epitaph, or postscript written by a female or male writer, or a chapter of a prosimetric novel (tanci 彈詞) by a woman writer, is identified by author, title, genre, and subgenre, and the digital image of the text with its title is shown in the page turner. Individual collections can be read online using it (Figure 3).

The more than a dozen Browse Indexes (liebiao chayue 列表查閱) on the search page provide convenient ways to look at global figures in many categories: collections by library, publication year, or by type; personal names, gender, ethnic groups, marital status; poem and prose genres and titles, poetic forms, and tune patterns; and more. The database design of MQWW was primarily conceptualized to serve as a literary research tool; it was not originally designed for biographical research. Scholarship and research, however, have indicated that family and kinship, geographical location and regional culture, and social networks and literary communities were significant factors affecting the education, marriage, and general life course of women as writers. This oversight was addressed by collaboration with the China Biographical Database (CBDB) at Harvard to create an API (Application Programming Interface) to MQWW biographical data stored in $\mathrm{CBDB}$, thus enabling users of MQWW to query CBDB through a link embedded on each author page in MQWW for easy query and return of structured 

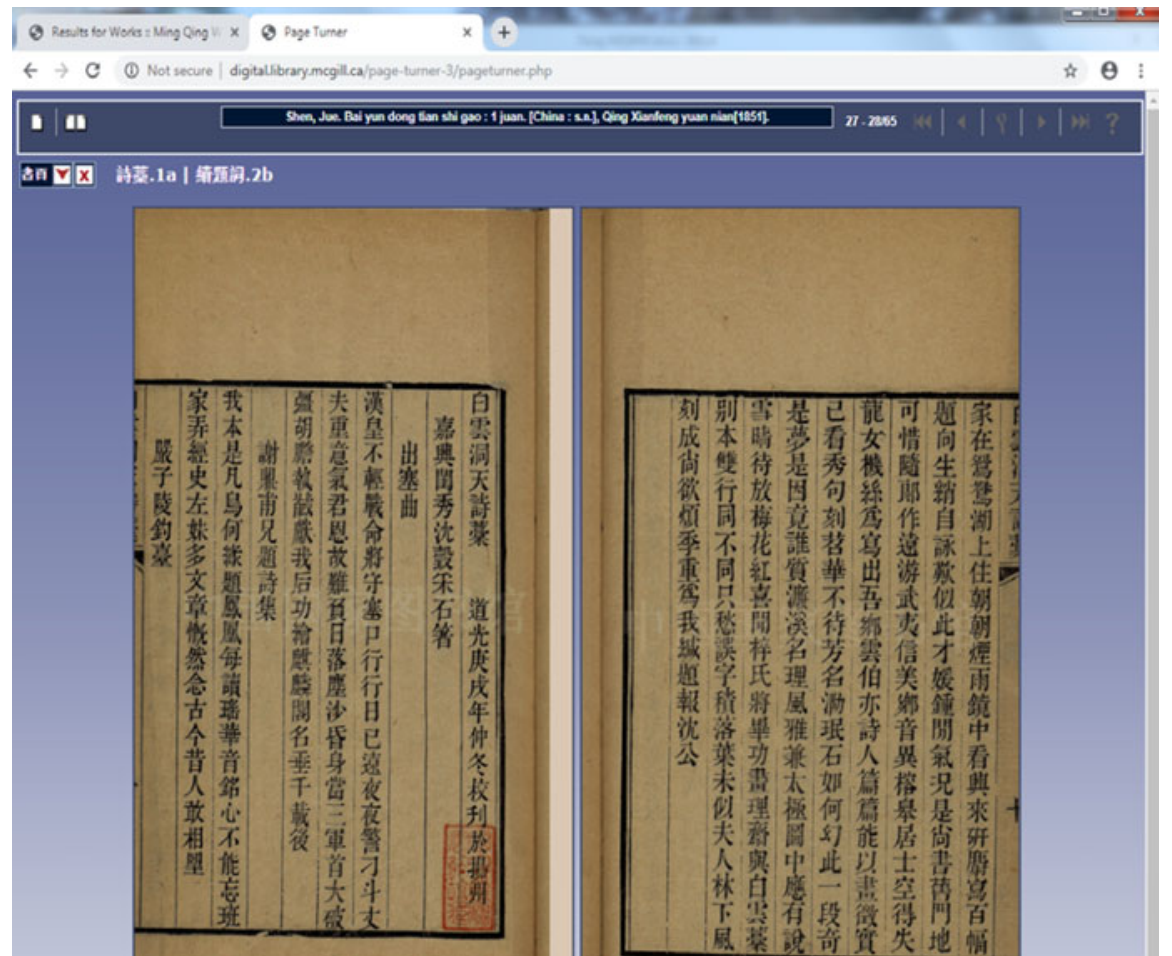

Figure 3. Page turner view: Bai yun dong tian shi gao, xutici.2b-shigao.1a

biographical data. Furthermore, in 2015 we followed the model set by CBDB to develop a downloadable Microsoft Access version of MQWW data to promote users' direct access to MQWW datasets for data analysis and other uses. ${ }^{4}$ The Access Database Research Tool was made available for free download, and it is updated annually in December to include new collections and thus new data. Although we have no way of tracking how the data are used in research, the monthly records of downloads for 2018 and 2019 indicate interest in their availability (see Table 1).

With the accessibility of both MQWW digitized texts and data, researchers are able to use common digital tools such as ArcGIS, statistical analysis software such as SPSS, Pajek, or Gephi to map and visualize the data, to do social network analysis, and to explore the circulation of women's books, the routes of movement in their lives, their temporal and geographical experiences, and many other topics for further study and analysis. $^{5}$

\footnotetext{
${ }^{4}$ Created by then Luce Postdoctoral Fellow Dr. Song SHI in collaboration with Elizabeth Thomson, Systems Analyst, and her colleagues, McGill Library Digital Initiatives.

${ }^{5}$ See the experiment by Jia-jia Hu with word frequency in women's poetry in MQWW, visualized in two word clouds, in "Exploring Lives of China's Ming-Qing Female Poets," Cultural and Religious Studies 5.9 (2017), 557-68; and Grace Fong and Song Shi, "Pilot Experiments with Data in Ming Qing Women's Writings (1368-1911)," presentation at the Quantitative Criticism Lab conference Digital Humanities
} 
Table 1. MQWW Access database download statistics 2018 and 2019

\begin{tabular}{|c|c|}
\hline Year-month / number of downloads & Year-month / number of downloads \\
\hline $2018-01 / 82$ & $2019-01 / 80$ \\
\hline $2018-02 / 0$ & $2019-02 / 58$ \\
\hline $2018-03 / 76$ & $2019-03 / 57$ \\
\hline $2018-04 / 89$ & $2019-04 / 68$ \\
\hline $2018-05 / 52$ & $2019-05 / 72$ \\
\hline $2018-06 / 59$ & $2019-06 / 79$ \\
\hline $2018-07 / 38$ & $2019-07 / 58$ \\
\hline $2018-08 / 63$ & $2019-08 / 82$ \\
\hline $2018-09 / 50$ & $2019-09 / 76$ \\
\hline $2018-10 / 59$ & $2019-10 / 51$ \\
\hline $2018-11 / 47$ & $2019-11 / 37$ \\
\hline $2018-12 / 59$ & $2019-12 / 18$ \\
\hline Total for 2018: 674 & Total for 2019: 656 \\
\hline
\end{tabular}

Table 2. Top 10 web sites by number of page requests

\begin{tabular}{lcccc}
\hline & No. of page requests & Rank in Top & No. of page requests & Rank in Top \\
Month & 2018 & 10 & 579 & 10 \\
\hline January & 271532 & 1 & 555661 & 1 \\
\hline February & 254532 & 1 & 665101 & 1 \\
\hline March & 323751 & 1 & 528872 & 1 \\
\hline April & 362478 & 1 & 380451 & 1 \\
\hline May & 253316 & 1 & 327365 & 1 \\
\hline June & 581304 & 1 & 420118 & 1 \\
\hline July & 346342 & 1 & 285912 & 2 \\
\hline August & 469946 & 1 & 84992 & 3 \\
\hline September & 323751 & 1 & 233880 & 1 \\
\hline October & 531284 & 1 & 234166 & 2 \\
\hline November & 480915 & 1 & 375350 & 1 \\
\hline December & 581304 & 1 & & 1 \\
\hline
\end{tabular}

Source: http://digital.library.mcgill.ca/statistics/index.html

beyond Modern English: Computational Approaches to Premodern and Non-Western Literature, Dartmouth College, April 24-25, 2019. 
Table 3. User breakdown by region

\begin{tabular}{lll}
\hline Rank & \multicolumn{1}{c}{2018} & \multicolumn{1}{c}{2019} \\
\hline 1 & Taiwan & Taiwan \\
\hline 2 & Hong Kong & Hong Kong \\
\hline 3 & United States & United States \\
\hline 4 & Canada & Canada \\
\hline 5 & United Kingdom & United Kingdom \\
\hline 6 & Japan & Japan \\
\hline 7 & China & China \\
\hline 8 & Singapore & Singapore \\
\hline 9 & South Korea & Germany \\
\hline 10 & Malaysia & South Korea \\
\hline
\end{tabular}

Judging by the monthly user statistics maintained by Digital Library McGill, MQWW has been fulfilling its intended purpose since the website was launched in 2005. Since the information was tracked beginning ten years ago in November 2009, MQWW has been consistently among the "Top 10 most popular digitization web sites by number of page requests" among the digital collections hosted by McGill University Library. Over the years MQWW has never gone below No. 5 and most of the time it has been No. 1. The total page requests per month range from over 200,000 to over 600,000 . In the published statistics for 2018 up to August 2019, with one exception, MQWW stayed at No. 1 each month (see Table 2).

The regional analysis of users by Google Analytics is revealing. The high ranks of Taiwan and Hong Kong suggest that users with academic background, English proficiency, and computer skills predominate in the Asia Pacific region, followed by similar users-academic background, Chinese proficiency, and computer skills-in the US and Canada. The top ten regions ranked by "clicks" for 2018 and 2019 are shown in Table $3 .^{6}$

As stated on the home page, the Ming Qing Women's Writings digital archive and database project is dedicated to the digitization of collections of writings by women in late imperial China, now also in Republican China. Scholarly research estimates approximately only 800 to 1,000 out of about 4,000 collections recorded in the most comprehensive catalogue of Chinese women's writings, Lidai funü zhuzuokao 歷代婦女著作考, are still extant. ${ }^{7}$ The project aims to preserve and make accessible on the internet this valuable cultural legacy for future generations of scholars, researchers, and other interested publics, thus building intellectual and technological infrastructure and creating opportunities to generate new methodologies in the fields of digital humanities and China studies.

\footnotetext{
${ }^{6}$ Information provided by Elizabeth Thomson using Google Analytics, October 7, 2019.

${ }^{7}$ Compiled by Hu Wenkai 胡文楷, first published by in 1957, revised edition 1985, and augmented edition by Shanghai guji chubanshe, 2008. Some titles in MQWW were not recorded in Hu Wenkai.
} 